\title{
Л.Ф. Черногор
}

\section{Каналы воздействия вариаций космических и атмосферных факторов на биосферу и человека}

\begin{abstract}
Обоснована челесообразность системного подхода при изучении каналов воздействия вариаций космической и атмосферной погоды на биосферу и человека. Изложены основы системной парадигмы. Установлены причины вариаций космической и атмосферной погоды, показана их взаимосвязь. Обсуждаются каналы воздействия этих вариаций на биосферу и человека. Сравниваются апериодические и квазипериодические возмущения физических полей, влияющие на биосферу и человека.

Ключевые слова: атмосферная погода, космическая погода, системный подход, биосфера, канальв воздействия, пульсаиии физических полей.
\end{abstract}

\section{ВВЕДЕНИЕ}

Биосфера, чаще всего, рассматривается либо обособленно, либо в качестве подсистемы в системе океан - суша - атмосфера (OCA). Система ОСА в основном формирует состояние атмосферной погоды.

Атмосферная погода - физическое состояние системы ОСА в каждом месте в каждом интервале времени. Климат усредненное на достаточно большом временном интервале состояние погоды. Естественно, что процессы в системе OCA, как и вариации атмосферной погоды (ВАП), влияют на биосферу и человека в частности. Известно, что биосфера объект не только земной, но и космический в том смысле, что она испытывает на себе влияние космических факторов - гравитации, процессов на Солнце, метеоров, потоков галактических лучей и т. д. Иначе говоря, биосфера в качестве подсистемы входит в систему Космос - Земля. Космические факторы формируют состояние космической погоды. Космическая погода физическое состояние геокосмоса (т. е. верхней атмосферы, ионосферы и магнитосферы) в каждом месте в каждом интер-

(C) Л.Ф. Черногор вале времени. Космический климат усредненное на достаточно большом временном интервале состояние космической погоды. В последнее время появились основания утверждать, что обе погодные системы связаны между собой $[12,14,18$, $20,21,24,29,31,35]$. Это означает, что на биосферу совместно (синергетически) воздействуют вариации как атмосферной, так и космической погоды.

Каналы воздействия системы ОСА на биосферу изучены недостаточно, хотя сам факт воздействия (в частности, метеочувствительность человека) известен давно. Еще хуже дело обстоит со знанием механизмов влияния вариаций космической погоды (ВКП) на биосферу и человека. Факт же воздействия этих вариаций обсуждается, начиная с XIX века. Высказывания о влиянии космоса на биосферу встречаются в работах В. И. Вернадского создателя учений о биосфере и ноосфере. Опираясь на данные исследований своих предшественников, А. Л. Чижевский основоположник гелиобиологии - впервые научно обосновал гипотезу о том, что значительное число солнечных и земных процессов - синхронны $[9,28]$. 
Возможные влияния ВАП и ВКП, воздействие физических полей на биосферу рассматривались многими авторами [3, 4, $6,7,10,11]$. Установлено, что указанные вариации существенно влияют на поведение биосферы, самочувствие и здоровье человека и, по-видимому, на социальные процессы. Из-за сложности процессов, многофакторности и синергетичности воздействий в системе Космос - Земля каналы влияния ВАП и ВКП изучены недостаточно. Предыдущим исследователям недоставало системного подхода к изучаемой проблеме. Для выявления механизмов и каналов воздействия ВАП и ВКП необходим системный подход к системе Космос - Земля в целом, к системе Солнце - межпланетная среда магнитосфера - ионосфера - атмосфера Земля (СМСМИАЗ) и, в частности, включение в эту систему биосферы (Б) и человека в качестве подсистемы.

Цель настоящей работы - изложение основ системного подхода к системе СМСМИАЗБ, обсуждение причин вариаций космической и атмосферной погоды, а также каналов воздействия этих вариаций на биосферу и человека.

\section{ОСНОВЫ СИСТЕМНОЙ ПАРАДИГМЫ}

Элементы системного подхода к системе СМСМИАЗБ разрабатывались многими специалистами из различных областей науки. Определенный итог подведен в работах $[12,14,18,20,21,24,31,35]$.

Основные положения системной парадигмы четко сформулированы автором в 1980-х гг. [12]. Они сводятся к следующему.

1. ВАП и ВКП могут быть адекватно описаны в рамках системного подхода. Объектом исследования служит система СМСМИАЗ.

2. Система СМСМИАЗ обладает свойствами иерархии. В систему в качестве подсистемы входит биосфера (человек), образуя систему СМСМИАЗБ.

3. Между подсистемами системы СМСМ ИАЗБ имеют место прямые и обратные, положительные и отрицательные связи.

4. СМСМИАЗБ - открытая система. В нее поступают излучение, вещество, энергия и энтропия как “сверху”, так и “снизу”.

5. СМСМИАЗБ - динамическая система.

6. СМСМИАЗБ - нелинейная система.

7. В системе СМСМИАЗБ возможны усложнение, самоорганизация и саморазвитие за счет использования внешних источников энергии, излучения, массы и т. д.

Открытые динамические нелинейные системы, находящиеся в метастабильном состоянии, сверхчувствительны к воздействию слабых внешних возмущений и флуктуаций. В таких системах возможны неустойчивости, бифуркации, самоорганизация, перемежаемость квазидетерминированных и хаотических режимов, триггерные процессы и т. п.

Схематическое строение системы, формирующей ВАП и ВКП, показано на рис. $1[12,24]$.

\section{ПРИЧИНЫ ВАРИАЦИЙ АТМОСФЕРНОЙ И КОСМИЧЕСКОЙ ПОГОДЫ}

ВКП в основном формируются нестационарными процессами на Солнце, в меньшей степени потоками галактических лучей, метеоров, падениями крупных космических тел, а также мощными земными, атмосферными, океаническими и антропогенными процессами.

Рассмотрим и сравним энергетику естественных (табл. 1) и антропогенных (табл. 2) процессов. Из таблиц видно, что энергии и мощности ряда естественных и антропогенных процессов могут быть сопоставимы. Это означает, что антропогенные процессы могут давать заметный вклад в формирование ВАП и ВКП, а отчасти и климата $[12,24]$. А также сравним потоки энергии “сверху” (табл. 3) и “снизу” 


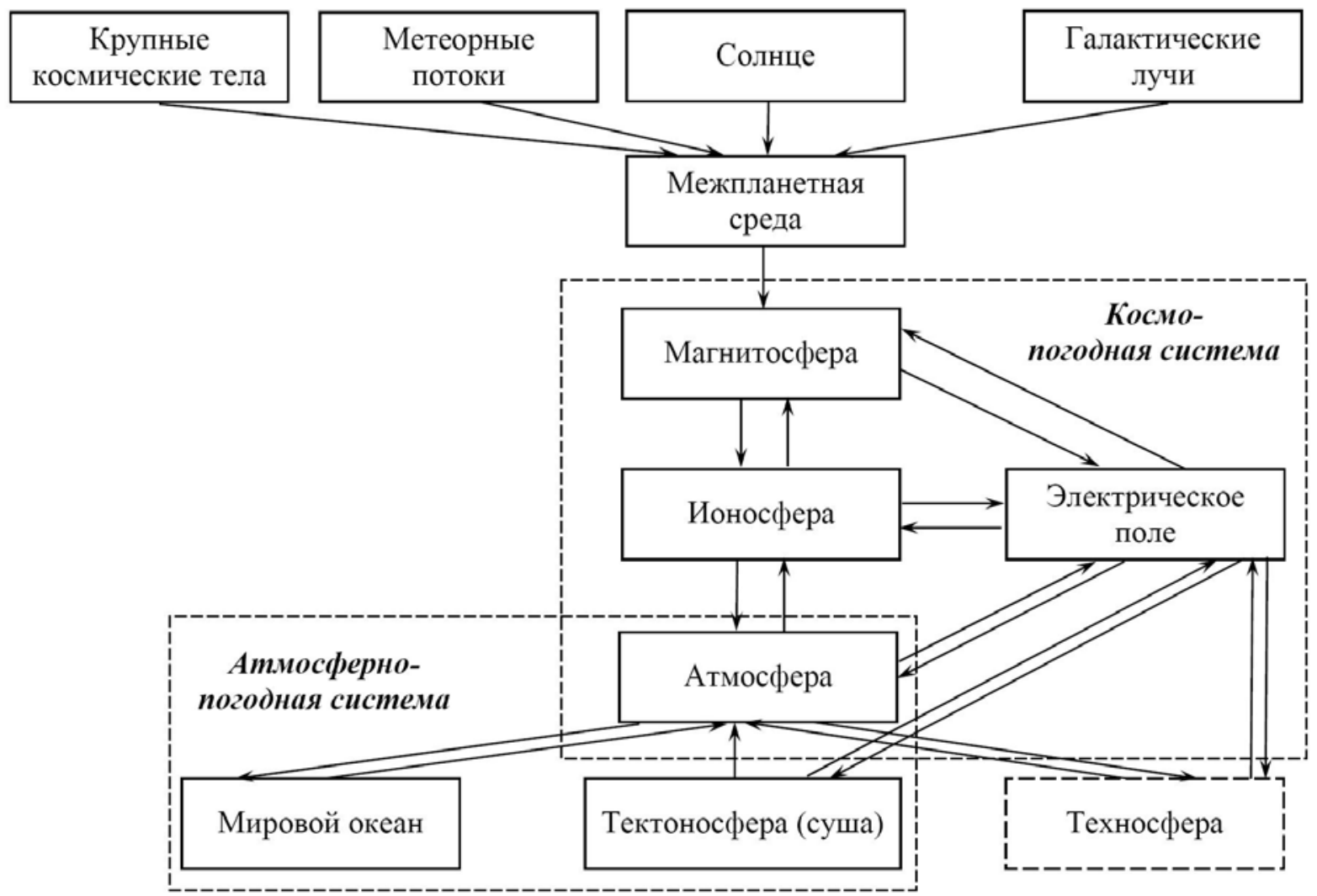

Рис. 1. Строение системы, формирующей вариации космической и атмосферной погоды

Таблица 1. Параметры естественных процессов

\begin{tabular}{|c|c|c|c|c|}
\hline Источник & $\begin{array}{c}\text { Энергия, } \\
\text { Дж }\end{array}$ & $\begin{array}{c}\text { Мощность, } \\
\text { Вт }\end{array}$ & \begin{tabular}{|c|} 
Продолжитель- \\
ность воздейст- \\
вия, с
\end{tabular} & Примечание \\
\hline Оптическое излучение Солнца & $10^{22}$ & $10^{17}$ & $10^{5}$ & В течение суток \\
\hline Солнечный ветер & $10^{17}$ & $10^{12}$ & $10^{5}$ & То же \\
\hline Метеорит & $10^{12}-10^{15}$ & $10^{12}-10^{15}$ & 1 & Воздействие на атмосферу \\
\hline Астероид & $10^{21}-10^{30}$ & $10^{23}-10^{30}$ & $10^{-2}-1$ & Удар о Землю \\
\hline Тунгусскийфеномен & $10^{16}$ & $10^{15}-10^{16}$ & $1-10$ & \\
\hline Молния & $10^{10}-10^{12}$ & $10^{10}-10^{12}$ & 1 & \\
\hline Глобальные ветры & $10^{20}$ & $10^{15}$ & $10^{5}$ & В течение суток \\
\hline Циклон & $10^{19}-10^{21}$ & $2 \cdot 10^{13}-2 \cdot 10^{15}$ & $5 \cdot 10^{5}$ & \\
\hline Ураган & $10^{18}-10^{20}$ & $10^{13}-10^{15}$ & $10^{5}$ & В течение суток \\
\hline Торнадо & $10^{11}-10^{13}$ & $10^{8}-10^{10}$ & $10^{3}$ & \\
\hline Вулкан & $10^{20}-10^{21}$ & $10^{15}-10^{19}$ & $10^{2}-10^{5}$ & \\
\hline Землетрясение & $10^{19}-10^{21}$ & $10^{17}-10^{18}$ & $10^{2}-10^{3}$ & \\
\hline Цунами & $10^{18}-10^{20}$ & $10^{16}-10^{19}$ & $10-10^{2}$ & \\
\hline Лесной пожар & $10^{18}-10^{19}$ & $10^{12}-10^{14}$ & $10^{5}-10^{6}$ & Площадь 1000 x 1000 км² \\
\hline Поток тепла из недр Земли & $3 \cdot 10^{18}$ & $3 \cdot 10^{13}$ & $10^{5}$ & В течение суток \\
\hline Биосфера & $10^{19}$ & $10^{14}$ & $10^{5}$ & Химическаяэнергия в течениесуток \\
\hline Человек & $3 \cdot 10^{7}$ & $3 \cdot 10^{2}$ & $10^{5}$ & То же \\
\hline
\end{tabular}


(табл. 4). Как и следовало ожидать, потоки энергии в виде оптического излучения Солнца являются главными. Другие потоки энергии "сверху" и “снизу" могут быть сопоставимы между собой, что свидетельствует о влиянии и тех, и других на ВАП и ВКП, о взаимодействии двух погодных систем [12, 14, 18, 20, 21, 24, 31, 35].

Взаимодействие подсистем в системе СМСМИАЗБ осуществляется при помощи потоков энергии и вещества. Важными переносчиками энергии и вещества являются волны различной физической природы, потоки тепла и частиц, включая высыпающиеся высокоэнергичные частицы $[12,14$, $18,20,21,24,31,35]$.
НЕСТАЦИОНАРНЫЕ ПРОЦЕССЫ НА СОЛНЦЕ - ОСНОВНАЯ ПРИЧИНА ВАРИАЦИЙ КОСМИЧЕСКОЙ ПОГОДЫ

Главной причиной ВКП, а отчасти и ВАП являются нестационарные процессы на Солнце. К ним относятся вспышки электромагнитного и корпускулярного излучений, выбросы корональной массы, воздействие ударной волны в солнечном ветре, бомбардировка магнитосферы плазменными и магнитными облаками солнечного происхождения.

Схема взаимодействия подсистем при возмущениях на Солнце показана на рис. 2 $[12,20,24]$. Из рисунка, в частности, видно

Таблица 2. Параметры антропогенных источников

\begin{tabular}{|c|c|c|c|c|}
\hline Источник & $\begin{array}{c}\text { Энергия, } \\
\text { Дж }\end{array}$ & $\begin{array}{c}\text { Мощность, } \\
\text { Вт }\end{array}$ & $\begin{array}{c}\text { Продолжитель- } \\
\text { ность воздейст- } \\
\text { вия, с }\end{array}$ & Примечание \\
\hline \multicolumn{5}{|l|}{ Ядерный взрыв: } \\
\hline одиночный & $4 \cdot 10^{17}$ & $4 \cdot 10^{24}$ & $10^{-7}$ & Эквивалент 100 Мт \\
\hline $\begin{array}{l}\text { всех боеприпасов } \\
\text { перспективный }\end{array}$ & $4 \cdot 10^{19}$ & $4 \cdot 10^{15}-4 \cdot 10^{16}$ & $10^{3}-10^{4}$ & Глобальный ядерный конфликт \\
\hline противоастероидный & $4 \cdot 10^{21}$ & $4 \cdot 10^{28}$ & $10^{-7}$ & \\
\hline Промышленный взрыв & $10^{11}-10^{12}$ & $10^{14}-10^{15}$ & $10^{-3}$ & Масса заряда $25-250$ т \\
\hline Авария на АЭС & $10^{18}$ & $10^{13}-10^{14}$ & $10^{4}-10^{5}$ & Масса топлива 100 т \\
\hline Взрыв крупной ракеты & $10^{11}-10^{14}$ & $10^{10}-10^{15}$ & $0,1-10$ & Масса топлива 1000 т \\
\hline Стартующая ракета: & & & & \\
\hline крупная & $10^{14}$ & $10^{11}-10^{12}$ & $10^{2}-10^{3}$ & То же \\
\hline перспективная & $10^{15}-10^{16}$ & $10^{12}-10^{14}$ & $10^{2}-10^{3}$ & Масса топлива $10^{4}-10^{5} \mathrm{~T}$ \\
\hline $\begin{array}{l}\text { Корректирующий двигатель } \\
\text { в космосе }\end{array}$ & $10^{8}-10^{10}$ & $10^{7}-10^{8}$ & $10-10^{2}$ & \\
\hline $\begin{array}{l}\text { Ядерная энергосистема } \\
\text { космического аппарата }\end{array}$ & $10^{14}$ & $10^{9}$ & $10^{5}$ & В течение суток \\
\hline Падение космического & & & & \\
\hline $\begin{array}{l}\text { аппарата: } \\
\text { крупного } \\
\text { перспективного }\end{array}$ & $\begin{array}{l}10^{12}-10^{13} \\
10^{14}-10^{15}\end{array}$ & $\begin{array}{l}10^{9}-10^{11} \\
10^{11}-10^{13}\end{array}$ & $\begin{array}{l}10^{2}-10^{3} \\
10^{2}-10^{3}\end{array}$ & $\begin{array}{l}\text { Macca: } \\
100 \mathrm{~T} \\
10^{3}-10^{4} \mathrm{~T}\end{array}$ \\
\hline ЛЭП & $10^{15}$ & $10^{10}$ & $10^{5}$ & В течение суток \\
\hline Излучение радиосистем & $10^{12}$ & $10^{7}$ & $10^{5}$ & То же \\
\hline Метеотрон & $10^{12}-10^{15}$ & $10^{9}-10^{10}$ & $10^{3}-10^{5}$ & \\
\hline Электростанция & $10^{14}-10^{15}$ & $10^{9}-10^{10}$ & $10^{5}$ & В течение суток \\
\hline Электростанции мира & $2 \cdot 10^{17}$ & $2 \cdot 10^{12}$ & $10^{5}$ & То же \\
\hline Мировое энергопотребление & $2 \cdot 10^{18}$ & $2 \cdot 10^{13}$ & $10^{5}$ & То же \\
\hline
\end{tabular}


влияние вариаций потока солнечного ветра (солнечной активности) на проявление солнечно-погодных связей (взаимодействие двух погодных систем). Промежуточным звеном служит модуляция потоков ГКЛ.

Нестационарные процессы на Солнце и, прежде всего, выбросы корональной массы вызывают геокосмические бури. Геокосмическая буря представляет собой синергетически взаимодействующие бури в магнитном поле, ионосфере, атмосфере и электрическом поле магнитосферно-ионосферно-атмосферного происхождения.

Энергетические характеристики геокосмической бури приведены в табл. 5 [31,

Таблица 3. Энергетические характеристики потоков “сверху”

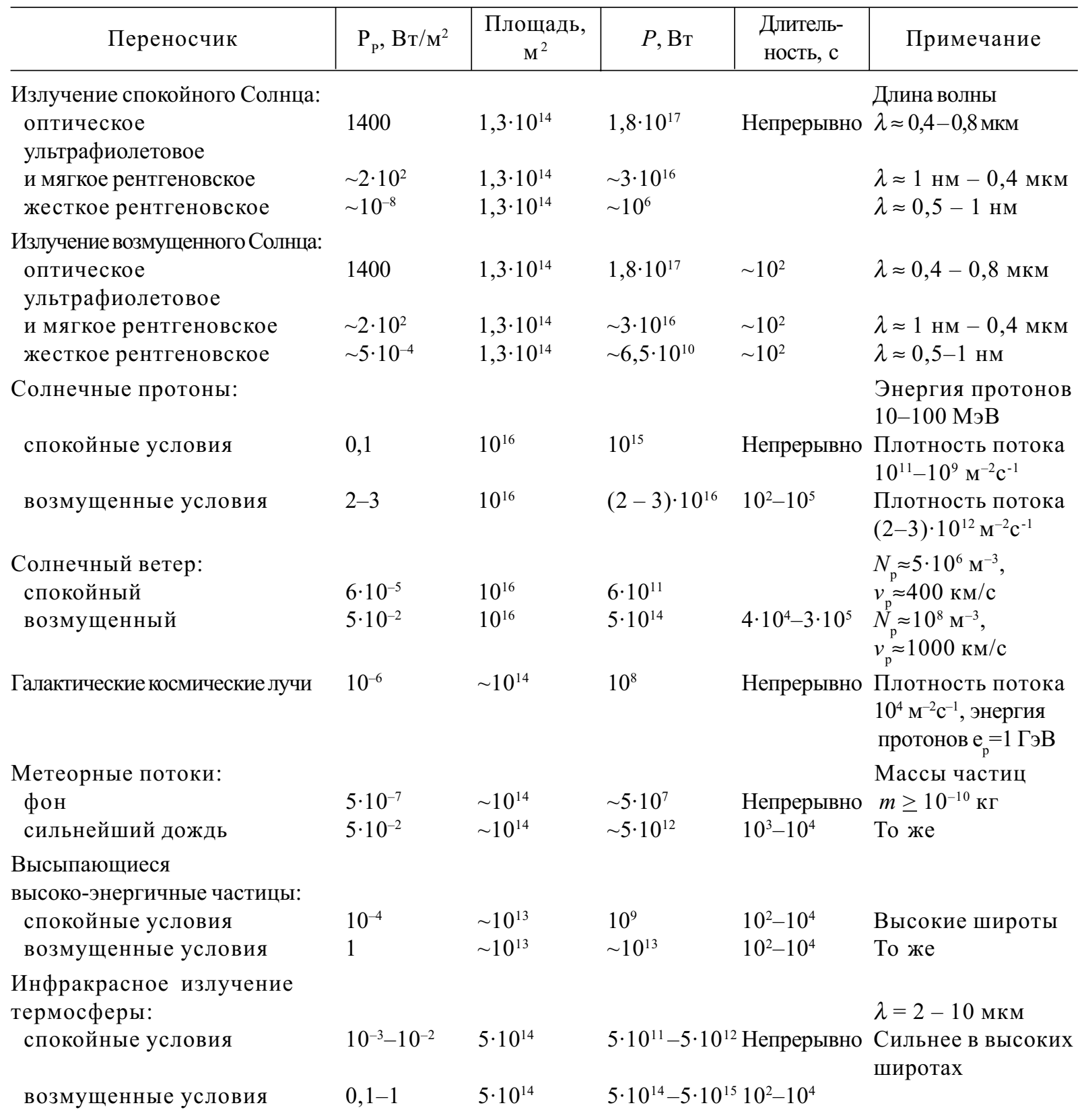


35]. Видно, что в процессе бури больше всего изменяется энергия электрического поля во всех внешних оболочках Земли. Существенно также варьируется тепловая энергия ионосферы. Магнитные возму- щения обычно невелики, но их роль может быть значительной.

Другими, менее интенсивными или более редкими, причинами ВКП и ВАП космического происхождения являются

Таблица 4. Энергетические характеристики потоков “снизу”

\begin{tabular}{|c|c|c|c|c|c|}
\hline Переносчик & $\mathrm{P}_{\mathrm{P}}, \mathrm{BT} / \mathrm{M}^{2}$ & $\begin{array}{c}\text { Площадь, } \\
\text { м }^{2}\end{array}$ & $P, \mathrm{BT}$ & $\begin{array}{l}\text { Длитель- } \\
\text { ность, с }\end{array}$ & Примечание \\
\hline $\begin{array}{l}\text { Инфракрасное излучение } \\
\text { поверхности Земли }\end{array}$ & $4 \cdot 10^{2}$ & $5 \cdot 10^{14}$ & $2 \cdot 10^{17}$ & Непрерывно & $\begin{array}{l}\text { Поглощается и } \\
\text { излучается } \\
\text { атмосферой }\end{array}$ \\
\hline Водяной пар & 80 & $5 \cdot 10^{14}$ & $4 \cdot 10^{16}$ & То же & $\begin{array}{l}\text { При конденсации } \\
\text { выделяется тепло } \\
\text { в атмосфере }\end{array}$ \\
\hline Конвекция воздуха & 30 & $5 \cdot 10^{14}$ & $1,5 \cdot 10^{16}$ & То же & \\
\hline Поток тепла из недр Земли & $6 \cdot 10^{-2}$ & $5 \cdot 10^{14}$ & $3 \cdot 10^{13}$ & То же & $\begin{array}{l}\text { Играет } \\
\text { незначительную } \\
\text { роль }\end{array}$ \\
\hline $\begin{array}{l}\text { Атмосферная турбулентность } \\
\text { Внутренние гравита-ционные }\end{array}$ & $1-10$ & $5 \cdot 10^{14}$ & $5 \cdot 10^{14}-5 \cdot 10^{15}$ & То же & До высот 100-120 км \\
\hline волны (ВГВ) & $0,1-1$ & $510^{14}$ & $5 \cdot 10^{13}-5 \cdot 10^{14}$ & То же & $\begin{array}{l}\text { Эффективно } \\
\text { диссипируют } \\
\text { в термосфере }\end{array}$ \\
\hline Приливные волны & $10^{-3}$ & $5 \cdot 10^{14}$ & $5 \cdot 10^{11}$ & То же & То же \\
\hline Планетарные волны & $10^{-3}$ & $5 \cdot 10^{14}$ & $5 \cdot 10^{11}$ & То же & То же \\
\hline Инфразвук & $10^{-4}-10^{-3}$ & $5 \cdot 10^{14}$ & $5 \cdot 10^{10}-5 \cdot 10^{11}$ & То же & $\begin{array}{l}\text { Достигает } \\
\text { F-области } \\
\text { ионосферы }\end{array}$ \\
\hline $\begin{array}{l}\text { Инфразвук от сильнейшего } \\
\text { землетрясения }\end{array}$ & $10^{2}-10^{3}$ & $10^{11}$ & $10^{13}-10^{14}$ & $10^{2}$ & То же \\
\hline $\begin{array}{l}\text { Электромагнитное излучение } \\
\text { сильнейшего землетрясения }\end{array}$ & $10^{-3}-10^{-2}$ & $10^{11}$ & $10^{8}-10^{9}$ & $10^{2}-10^{3}$ & $\begin{array}{l}\text { Достигает } \\
\text { ионосферы } \\
\text { и магнитосферы }\end{array}$ \\
\hline $\begin{array}{l}\text { Акустическое излучение } \\
\text { сильнейшей молнии }\end{array}$ & $10^{-3}$ & $10^{9}$ & $10^{6}$ & $\sim 1$ & $\begin{array}{l}\text { Диссипирует } \\
\text { в атмосфере }\end{array}$ \\
\hline \multicolumn{6}{|l|}{ Электромагнитное излучение } \\
\hline сильнейшей молнии & $10^{-3}$ & $10^{9}$ & $10^{6}$ & $\sim 1$ & $\begin{array}{l}\text { Достигает } \\
\text { ионосферы } \\
\text { и магнитосферы }\end{array}$ \\
\hline $\begin{array}{l}\text { Акустическое излучение } \\
\text { мировой грозовой активности }\end{array}$ & $10^{-3}$ & $10^{12}$ & $10^{9}$ & Непрерывно & $\begin{array}{l}\text { Диссипирует } \\
\text { в атмосфере }\end{array}$ \\
\hline $\begin{array}{l}\text { Электромагнитное излучение } \\
\text { мировой грозовой активности }\end{array}$ & $10^{-3}$ & $10^{12}$ & $10^{9}$ & То же & $\begin{array}{l}\text { Достигает } \\
\text { ионосферы } \\
\text { и магнитосферы }\end{array}$ \\
\hline
\end{tabular}


метеорные потоки и падения достаточно крупных космических тел. Метеорные потоки привносят в систему вещество из космоса, формируют в ионосфере пылевую плазму, нагревают верхнюю атмосферу, создают дополнительную ионизацию и, что особенно важно для биосферы, являются источниками инфразвуковых волн. Падения крупных космических тел способны изменить не только космическую погоду, но и существенно повлиять на космический климат, вызвать эффект “астероидной зимы” кардинально модифицировать биосферу и даже ее уничтожить. Подобные катаклизмы в истории Земли были. К счастью, чем больше размер космического тела, тем реже такие тела сталкиваются с Землей. Например, тела, подобные Тунгусскому, падают на Землю один раз в 100-300 лет. Падения крупных космических тел сопровождаются генерацией возмущений электрического, магнитного, электромагнитного и инфразвукового полей, существенно воздействующих на биосферу и человека.

\section{ЗЕМНЫЕ ПРИЧИНЫ ВАРИАЦИЙ АТМОСФЕРНОЙ И КОСМИЧЕСКОЙ ПОГОДЫ}

Обсудим кратко земные причины ВАП и ВКП, вызванные источниками сейсмического, вулканического и атмосферного (атмосферно-океанического) происхождения.

Сейсмические процессы сопровождаются генерацией квазистатических электрических и магнитных полей, электромагнитного излучения, выходом газов (в том числе и радиоактивного радона), нагревом приземной атмосферы, генерацией инфразвука и внутренних гравитационных волн (ВГВ). Взаимодействие подсистем и основные процессы при этом изображены на рис. 3.

Энергетические характеристики полей сейсмического происхождения приведены в табл. 6 [12, 24]. Видно, что эти поля обладают значительной энергетикой, они способны влиять на ВАП и ВКП.

Вариации атмосферной и космической

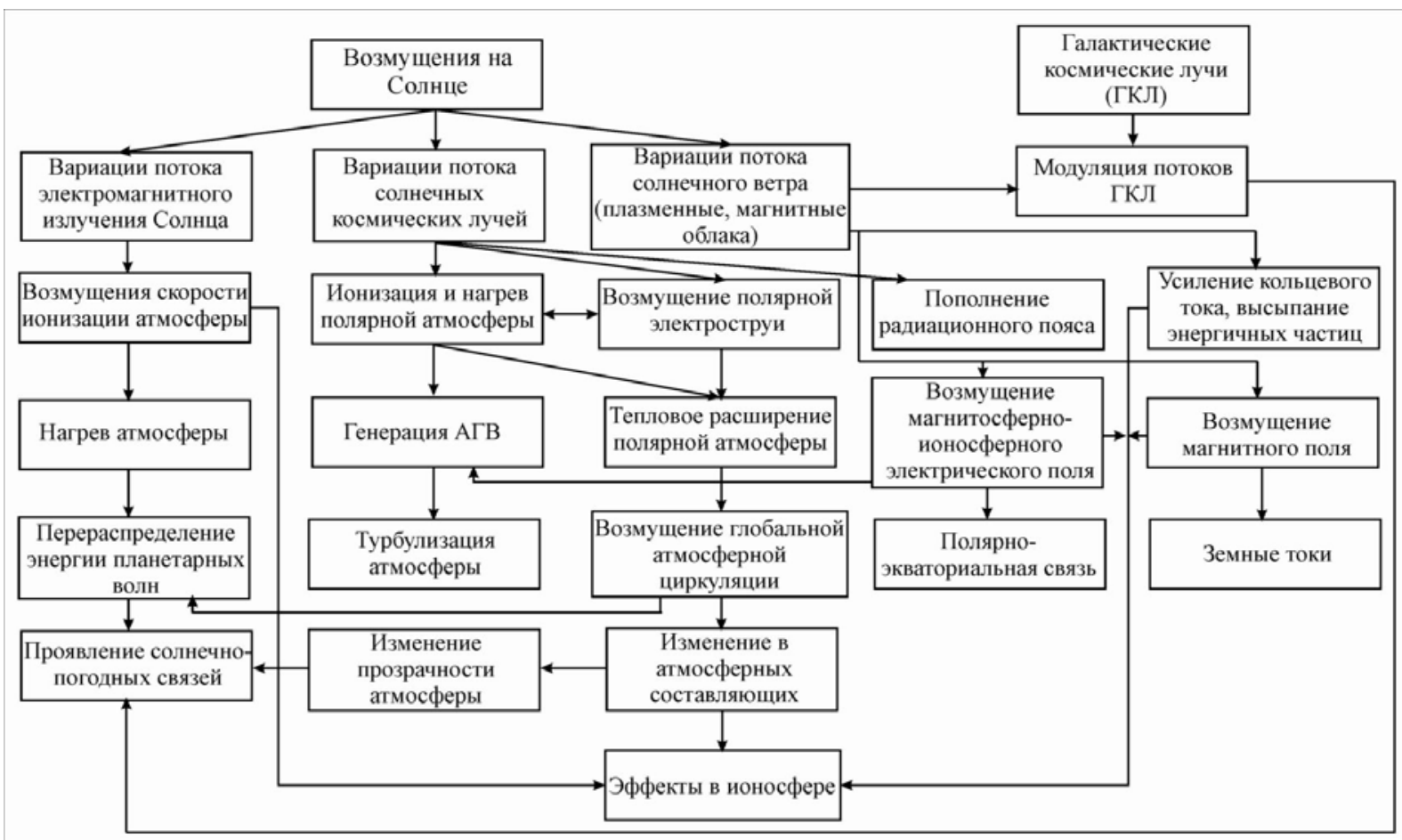

Рис. 2. Схема взаимодействия подсистем в системе СМСМИАЗ (АГВ - акустико-гравитационные волны) 
Таблица 5. Энергетические характеристики геокосмических бурь

\begin{tabular}{|c|c|c|c|c|c|}
\hline Область геокосмоса & $\begin{array}{c}\text { Энергия, } \\
\text { Дж }\end{array}$ & $\begin{array}{c}\text { Мощность, } \\
\text { Вт }\end{array}$ & $\begin{array}{l}\text { Продолжи- } \\
\text { тельность, с }\end{array}$ & $\begin{array}{c}\text { Относительные } \\
\text { изменения } \\
\text { энергии }\end{array}$ & Примечание \\
\hline \multirow[t]{2}{*}{ Магнитосфера } & $10^{16}$ & $10^{12}$ & $10^{4}$ & $10^{-2}$ & $\begin{array}{l}\text { Энергия магнитного } \\
\text { поля }\end{array}$ \\
\hline & $10^{8}-10^{10}$ & $10^{4}-10^{6}$ & $10^{4}-10^{5}$ & $10^{2}-10^{4}$ & $\begin{array}{l}\text { Энергия электрического } \\
\text { поля }\end{array}$ \\
\hline \multirow[t]{2}{*}{ Ионосфера } & $10^{12}$ & $10^{8}$ & $10^{4}$ & \pm 1 & Тепловая энергия \\
\hline & $10^{5}-10^{7}$ & $10-10^{3}$ & $10^{4}-10^{5}$ & $10^{2}-10^{4}$ & $\begin{array}{l}\text { Энергия электрического } \\
\text { поля }\end{array}$ \\
\hline Термосфера & $10^{15}-10^{17}$ & $10^{11}-10^{13}$ & $10^{4}-10^{5}$ & $10^{-3}-10^{-1}$ & Тепловая энергия \\
\hline Приземная атмосфера & $10^{11}-10^{12}$ & $10^{6}-10^{8}$ & $10^{4}-10^{5}$ & $1-10$ & $\begin{array}{l}\text { Энергия атмосферного } \\
\text { электрического поля }\end{array}$ \\
\hline
\end{tabular}

погоды возникают в результате мощных потоков водяных паров от Мирового океана (особенно в приэкваториальных широтах), их конденсации, выделения латентного (скрытого) тепла, зарождения и усиления мощных атмосферных вихрей (типа тайфуна, тропического циклона), генерации инфразвука, ВГВ, квазистатических электрических и магнитных полей и электромагнитного излучения. Основные процессы

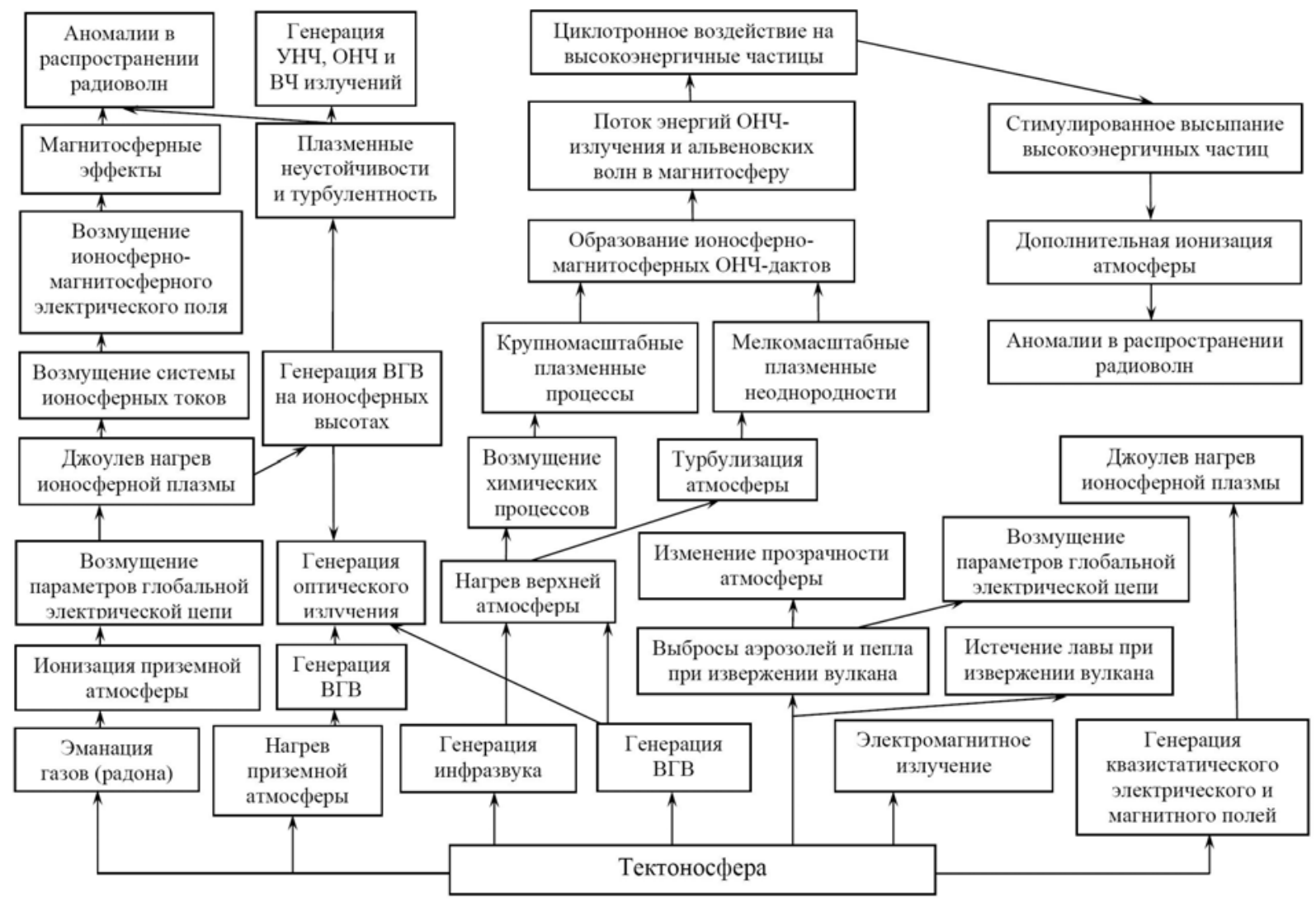

Рис. 3. Вариации атмосферной и космической погоды сейсмического и вулканического происхождения (УНЧ, ОНЧ и ВЧ - ультра низкочастотные, очень низкочастотные и высокочастотные излучения) 
Таблица 6. Энергетические характеристики полей сейсмического происхождения

\begin{tabular}{|c|c|c|c|c|}
\hline Поле & Энергия, Дж & Мощность, Вт & $\begin{array}{l}\text { Продолжи- } \\
\text { тельность, с }\end{array}$ & Примечание \\
\hline \multicolumn{5}{|l|}{ Электромагнитное: } \\
\hline$f \leq 10$ Гц & $10^{10}-10^{11}$ & $10^{8}$ & $10^{2}-10^{3}$ & $\begin{array}{l}\text { Достигает ионосферы } \\
\text { и магнитосферы }\end{array}$ \\
\hline$f=10^{3}-10^{4} \Gamma ц$ & $10^{13}-10^{14}$ & $10^{11}$ & $10^{2}-10^{3}$ & То же \\
\hline$f=10^{5}-10^{6} \Gamma ц$ & $10^{15}-10^{16}$ & $10^{13}$ & $10^{2}-10^{3}$ & $\begin{array}{l}\text { Сильно ослабляется } \\
\text { в литосфере }\end{array}$ \\
\hline Электрическое & $10^{9}$ & $10^{4}-10^{6}$ & $10^{3}-10^{5}$ & Достигает ионосферы \\
\hline Магнитное & $10^{10}$ & $10^{8}$ & $10^{2}$ & То же \\
\hline Инфразвуковое & $10^{15}-10^{16}$ & $10^{13}-10^{14}$ & $10^{2}$ & Достигает высот 300 км \\
\hline
\end{tabular}

в подсистемах и их взаимодействие представлены на рис. 4.

Параметры инфразвука, вызванного океаническим волнением, приведены в табл. 7 [18]. Оказывается, что значения частоты близки к одной из собственных частот сердца человека (см. далее табл. 11).
Значительные ВАП и, в меньшей степени, ВКП вызываются извержениями вулканов.

Вулканическая активность сопровождается следующими эффектами.

- Взрывоподобное выделение энергии, генерация акустико-гравитационных волн

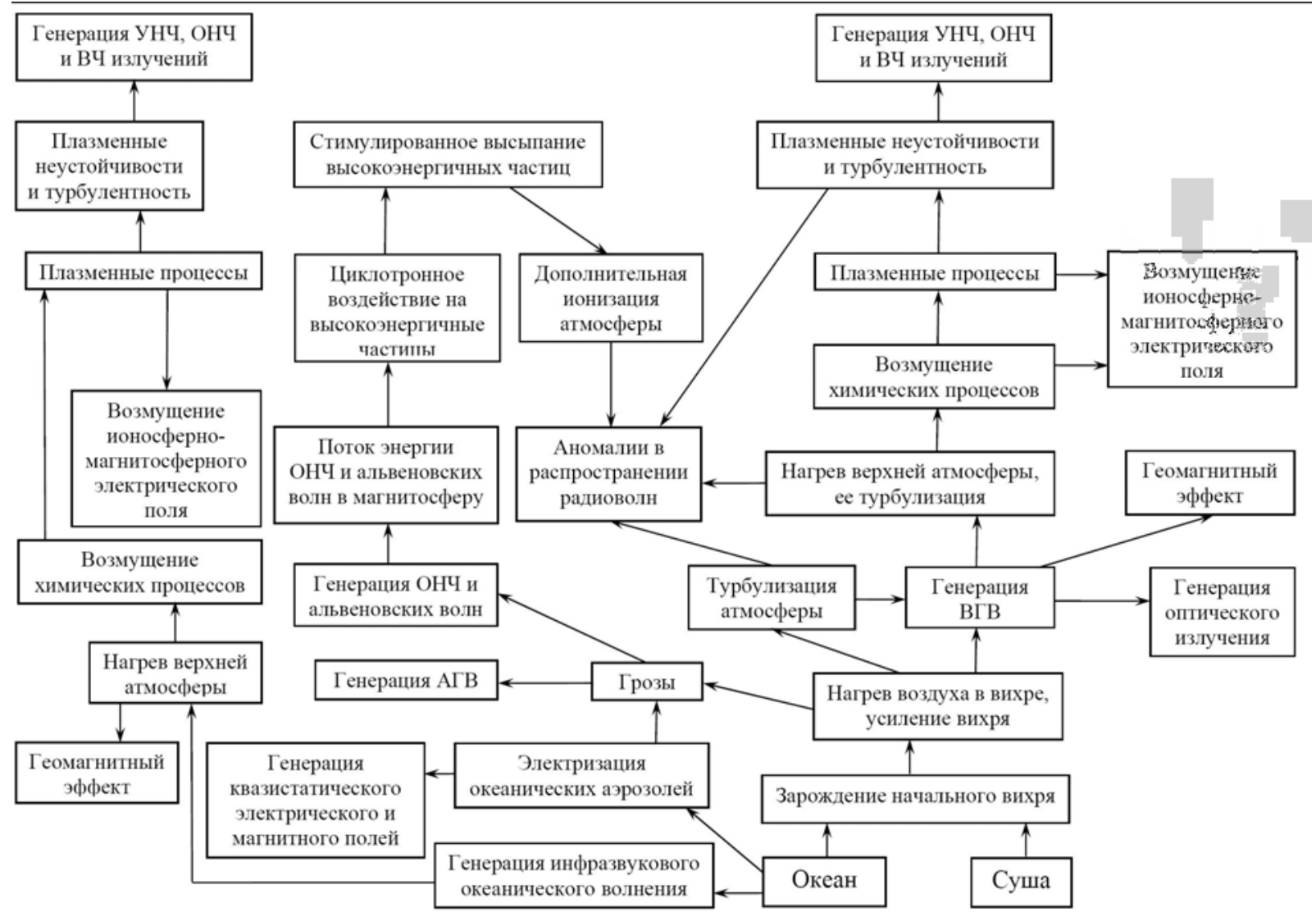

Рис. 4. Вариации атмосферной и космической погоды атмосферного (атмосферно-океанического) происхождения 
(АГВ), возникновение вариаций геомагнитного и геоэлектрического полей, изменение параметров глобальной электрической цепи.

- Генерация сейсмических волн.

- Выбросы аэрозолей в тропосферу и стратосферу.

- Распространение АГВ в верхнюю атмосферу, их диссипация, нагрев и турбулизация верхней атмосферы.

- Изменение проводимости ионосферы и системы электрических токов.

- Генерация крупномасштабной и мелкомасштабной плазменной турбулентности.

- Возникновение плазменных эффектов в ионосфере и магнитосфере.

Большое значение имеют вторичные эффекты (вариации свечения атмосферы, высыпания частиц, аномалии в распространении радиоволн, генерация электромагнитных шумов и др.).

Особое место занимают триггерные эффекты (изменение прозрачности атмосферы, охлаждение земной поверхности, изменение параметров динамических процессов в атмосфере и др.). В этом случае энергия вторичных процессов значительно (на пять - шесть порядков) превышает энергию первичных процессов. В частности, может возникнуть эффект “вулканической зимы”.

\section{АНТРОПОГЕННЫЕ ИСТОЧНИКИ ВАРИАЦИЙ АТМОСФЕРНОЙ И КОСМИЧЕСКОЙ ПОГОДЫ}

Существует целый ряд мощных источников антропогенного происхождения, способных влиять на ВАП и даже на ВКП. К ним относятся $[5,12,21,24,25]$ :

- старты и полеты ракет;

- мощные промышленные взрывы:

- взрывные работы на горно-обогатительных комбинатах;

- военные действия;

- крупные аварии на военных базах и складах;

- крупные аварии на энергоемких производствах, при транспортировке энергоносителей и т. п.

Приведем несколько примеров крупных аварий на военных базах, имевших место

Таблица 7. Основные параметры акустического излучения, генерируемого океаническими волнами

\begin{tabular}{l|lllllllll}
\hline$v_{0}, \mathrm{M} / \mathrm{c}$ & $f_{m}, \mathrm{м} \Gamma ц$ & $T_{m}, \mathrm{c}$ & $\Pi_{a 0}, \mathrm{BT} / \mathrm{M}^{2}$ & $\delta p_{a}, \Pi \mathrm{a}$ & $\mathrm{v}_{w}, \mathrm{M} / \mathrm{c}$ & $S_{a} \cdot 10^{-9}, \mathrm{M}^{2}$ & $P_{a}, \mathrm{BT}$ \\
\hline 10 & 147 & 6,8 & $3,7 \cdot 10^{-7}$ & $1,3 \cdot 10^{-2}$ & $2,9 \cdot 10^{-5}$ & 0,7 & $2,6 \cdot 10^{2}$ \\
15 & 98 & 10,2 & $9,2 \cdot 10^{-6}$ & $6,4 \cdot 10^{-2}$ & $1,4 \cdot 10^{-4}$ & 0,7 & $6,5 \cdot 10^{3}$ \\
20 & 74 & 13,6 & $9,2 \cdot 10^{-5}$ & 0,2 & $4,5 \cdot 10^{-4}$ & 0,7 & $6,5 \cdot 10^{4}$ \\
25 & 59 & 17 & $5,5 \cdot 10^{-4}$ & 0,5 & $1,1 \cdot 10^{-3}$ & 0,85 & $4,7 \cdot 10^{5}$ \\
30 & 49 & 20,4 & $2,4 \cdot 10^{-3}$ & 1 & $2,3 \cdot 10^{-3}$ & 0,85 & $2 \cdot 10^{6}$ \\
35 & 42 & 23,8 & $8,1 \cdot 10^{-3}$ & 1,9 & $4,3 \cdot 10^{-3}$ & 1 & $8,1 \cdot 10^{6}$ \\
40 & 37 & 27,2 & $2,4 \cdot 10^{-2}$ & 3,3 & $7,5 \cdot 10^{-3}$ & 1,2 & $2,9 \cdot 10^{7}$ \\
50 & 29 & 34 & 0,14 & 7,9 & $1,8 \cdot 10^{-2}$ & 1,4 & $2 \cdot 10^{8}$ \\
60 & 25 & 40,8 & 0,6 & 16,3 & $3,7 \cdot 10^{-2}$ & 1,6 & $9,6 \cdot 10^{8}$ \\
70 & 21 & 47,6 & 2,1 & 30,4 & $6,9 \cdot 10^{-2}$ & 1,8 & $3,8 \cdot 10^{9}$ \\
80 & 18 & 54,4 & 6 & 51,4 & 0,12 & 2,3 & $1,4 \cdot 10^{10}$ \\
90 & 16 & 61,2 & 15,5 & 82,7 & 0,19 & 2,8 & $4,3 \cdot 10^{10}$ \\
\hline
\end{tabular}

Здесь $v_{0}$ - тангенциальная составляющая скорости ветра; $f_{m}$ - частота, соответствующая максимуму излучения инфразвука; $T_{m}$ - период, соответствующий максимуму излучения инфразвука; П $a 0-$

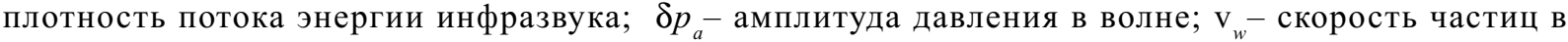
волне; $S_{a}-$ площадь акустического источника; $P_{a}-$ мощность акустического излучения. 
в последние годы в Украине [15-17, 19, 22].

1) 10-11 октября 2003 г. авария вблизи г. Артемовска. Общая масса боеприпасов 3,17 кт (масса прореагировавших боеприпасов - 1,7 кт), энергосодержание - 15,2 ТДж (энергосодержание прореагировавших боеприпасов - 8,4 ТДж), энергия акустического излучения - порядка единиц ТДж, средняя мощность - порядка 100 МВт.

2) 6-15 мая 2004 г. авария вблизи г. Мелитополя. Масса боеприпасов - 91 кт (масса прореагировавших боеприпасов - 18 кт), энергосодержание - 90 ТДж (энергосодержание прореагировавших боеприпасов - 20 ТДж), энергия акустического излучения - порядка 10 ТДж, средняя мощность - порядка 100 МВт.

3) 27-31 августа 2008 г. авария вблизи г. Лозовая. Масса боеприпасов - около 100 кт, энергосодержание - около 100 ТДж, энергия акустического излучения - порядка 10 ТДж, средняя мощность - порядка 100 $\mathrm{MB}$.

В качестве примеров крупных аварий на энергоемких производствах и при транспортировке энергоносителей приведем следующие [23].

1) 2004 г. авария на газопроводе Уренгой - Помары - Ужгород на участке между компрессорными станциями № 36 и № 37 .

2) 7 мая 2007 г. авария на газопроводе Уренгой - Помары - Ужгород вблизи с. Лука Таращанского района Киевской области.

3) 6 декабря 2007 г. авария на газопроводе Уренгой - Помары - Ужгород на участке между компрессорными станциями № 36 и № 37 . Масса прореагировавшего вещества - 2,6 кт, энерговыделение - 130 ТДж, максимальная мощность горения около 1 ТВт, энергия акустического излучения - около 1 ГДж, энергия сейсмической волны - около 1 МДж.

Одним из важнейших факторов влияния вытекания газа при авариях на подземных его хранилищах является генерация мощного инфразвукового излучения в полосах частот, соответствующих основным ритмам мозга человека (табл. 8) [23]. Из табл. 8 видно, что в зависимости от площади отверстия, через которое происходит утечка газа, мощность акустического излучения изменяется от единиц киловатт до единиц гигаватт. Следует ожидать исключительно сильного влияния этого излучения на мозг и психику человека.

Эффекты региональных неядерных войн на примере военных действий в феврале марте 2003 г. в Ираке детально проанализированы в предыдущей работе [13].

Схема взаимодействия подсистем в результате антропогенного воздействия приведена на рис. 5. Видно, что энерговыделение на поверхности Земли и в приземной атмосфере может приводить к определенным процессам в верхней атмосфере, ионосфере и даже магнитосфере.

\section{ВЛИЯНИЕ НА БИОСФЕРУ И ЧЕЛОВЕКА}

Биосфера (в т.ч.человек, человечество) входят в качестве подсистемы в систему СМСМИ АЗБ, которая, как уже отмечалось, является открытой динамической и нелинейной. Этой системе свойственны сложность и

Таблица 8. Мощности акустического излучения при пожаре на подземном газовом хранилище в полосах частот, соответствующих $\delta$-, $\boldsymbol{\theta}$-, $\boldsymbol{\alpha}$ - и $\boldsymbol{\beta}$-ритмам мозга человека

\begin{tabular}{llllllll|l|l}
\hline$S_{0}, \mathrm{M}^{2}$ & 1 & 3 & 10 & 30 & $10^{2}$ & $3 \cdot 10^{2}$ & $10^{3}$ \\
$P_{a \delta}, \mathrm{MBT}$ & $1,2 \cdot 10^{-3}$ & $1,8 \cdot 10^{-2}$ & 0,4 & 6 & $1,2 \cdot 10^{2}$ & $1,6 \cdot 10^{3}$ & $3,3 \cdot 10^{3}$ \\
$P_{a \theta}, \mathrm{MBT}$ & $1,1 \cdot 10^{-2}$ & 0,2 & 3,4 & 50 & $4,4 \cdot 10^{2}$ & $1,2 \cdot 10^{3}$ & $2,2 \cdot 10^{3}$ \\
$P_{a \alpha}, \mathrm{MBT}$ & $5,5 \cdot 10^{-2}$ & 0,8 & 16 & $1,1 \cdot 10^{2}$ & $3,2 \cdot 10^{2}$ & $6 \cdot 10^{2}$ & $10^{3}$ \\
$P_{a \beta}, \mathrm{MBT}$ & 1,4 & 1,5 & 66 & $1,3 \cdot 10^{2}$ & $2,5 \cdot 10^{2}$ & $4,3 \cdot 10^{2}$ & $7,2 \cdot 10^{2}$ \\
\hline
\end{tabular}


способность к самоорганизации, в ней следует ожидать синергетического воздействия на подсистемы.

В свою очередь, человек - открытая динамическая нелинейная биофизическая система. Вблизи метастабильных состояний она очень чутко реагирует на внешние весьма слабые возмущения как апериодические, так и квазипериодические и особенно хаотические [1, 2, 26, 27, 30, 34]. При этом в системе конкурируют квазидетерминированные и хаотические процессы $[32,33]$.

К уровням организации живой материи, на которых осуществляется воздействие вариаций атмосферной и космической погоды, отнесем следующие:

- клеточный,

- органный,

- организменный,
- популяционно-видовой (социальный),

- синергетический.

Основными каналами воздействия вариаций атмосферной и космической погоды на биосферу и человека являются:

- возмущения электрического поля,

- возмущения магнитного поля,

- возмущения барического поля,

- синергетическое воздействие.

Основные параметры физических полей перечислены в табл. 9. Видно, что относительные возмущения могут быть значительными.

Кроме апериодических возмущений, на человека действуют периодические возмущения (пульсации). Их основные параметры приведены в табл. 10. Из сравнения табл. 9 и 10 видно, что амплитуда пульсаций значительно меньше величины апериодических возмущений. В то же время

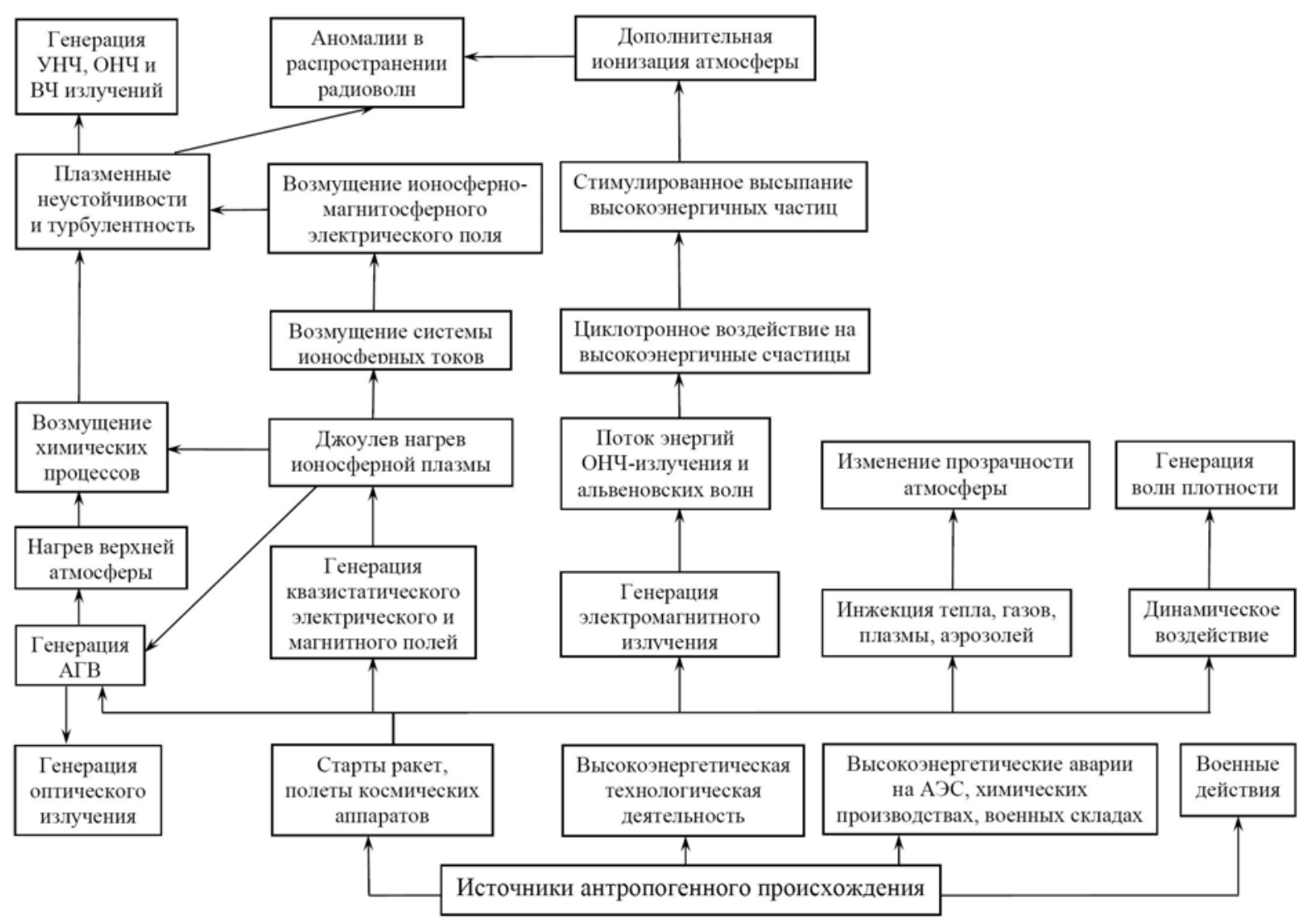

Рис. 5. Вариации атмосферной и космической погоды антропогенного происхождения 
Таблица 9. Параметры апериодических возмущений электрического, магнитного и барического полей, воздействующих на человека

\begin{tabular}{|c|c|c|c|c|c|}
\hline Поле & $\begin{array}{l}\text { Фоновое } \\
\text { значение }\end{array}$ & Возмущение & $\begin{array}{c}\text { Относительное } \\
\text { возмущение }\end{array}$ & $\begin{array}{c}\text { Характерное } \\
\text { время } \\
\text { возмущения, с }\end{array}$ & \begin{tabular}{|c|} 
Скорость \\
изменения \\
относительных \\
возмущений, $\mathrm{c}^{-1}$
\end{tabular} \\
\hline Электрическое & $\sim 100 \mathrm{~B} / \mathrm{M}$ & $10^{2}-10^{5} \mathrm{~B} / \mathrm{M}$ & $1-10^{3}$ & $10^{3}-10^{5}$ & $10^{-5}-1$ \\
\hline Магнитное & $5 \cdot 10^{-5}$ Тл & $5 Ч 10^{-7}$ Тл & $10^{-2}$ & $10^{3}-10^{5}$ & $10^{-7}-10^{-5}$ \\
\hline Барическое & $10^{3} \Pi \mathrm{a}$ & $<10^{2} \Pi \mathrm{a}$ & $<10^{-1}$ & $10^{3}-10^{5}$ & $10^{-6}-10^{-4}$ \\
\hline
\end{tabular}

скорость изменения относительных изменений физических полей в $10-10^{4}$ раз больше для пульсаций. По этой причине воздействие пульсаций на организм человека может быть намного сильнее. Особенно значительна роль тех пульсаций, частота которых близка к собственной частоте пульсаций органов человека (в Гц):

\begin{tabular}{l|c}
\hline \multicolumn{1}{c|}{ Орган } & \multicolumn{1}{c}{ Частота, Гц } \\
\hline Кишечник & $10^{-2}$ \\
Легкие & $10^{-1}-1$ \\
Сердце & $<3 \cdot 10^{-3}, 3 \cdot 10^{-3}-4 \cdot 10^{-2}$, \\
& $10^{-2}-10^{-1}, 10^{-1}-1$ \\
Мозг & $0-4,4-8,8-14,14-40$
\end{tabular}
Нервные волокна $10^{2}-10^{3}$

Установлено, что ВАП и ВКП воздействуют прежде всего на сердечно-сосудистую систему человека и механизмы ее регуляции $[1,2,26,27,30,34]$.

\section{ОБСУЖДЕНИЕ}

Выбросы корональной массы Солнца, плазменных и магнитных облаков, воздействие ударных волн в солнечном ветре, потоки корпускул и всплески электромагнитного излучения - основные причины систематических ВКП. Определенный вклад в эти вариации дают также усиливающиеся метеорные потоки, падения крупных космических тел, флуктуации потоков галактических лучей. Ощутимый вклад в ВКП могут вносить высокоэнергетические процессы на Земле, под ее поверхностью, в приземной атмосфере, ВАП и антропогенное воздействие на атмосферу и геокосмос.

ВКП и ВАП, часто связанные между собой, сопровождаются генерацией возмущений геомагнитного, геоэлектрического и акустического полей. При этом изменяется не только квазистационарная составляющая полей, но и генерируются квазипериодические волновые пакеты (пульсации) этих полей в широком диапазоне периодов $T$ (от $10^{-2}$ до $10^{4} \mathrm{c}$ ) или частот (от $10^{2}$ до $10^{-4}$ Гц) и длительностью от 1 с до нескольких часов.

С точки зрения влияния на биосферу и человека, по-видимому, более важными являются не медленные изменения квазистационарных составляющих полей во времени, а их пульсации.

Максимальные изменения индукции

Таблица 10. Параметры пульсаций электрического, магнитного и барического полей, воздействующих на человека

\begin{tabular}{l|l|l|l|l|l}
\hline \multicolumn{1}{c|}{ Поле } & Амплитуда & $\begin{array}{c}\text { Относительная } \\
\text { амплитуда }\end{array}$ & \multicolumn{1}{|l}{ Период, с } & $\begin{array}{c}\text { Скорость } \\
\text { изменения } \\
\text { относительных } \\
\text { возмущений, } \mathrm{c}^{-1}\end{array}$ & $\begin{array}{c}\text { Отношение } \\
\text { скоростей }\end{array}$ \\
\hline Электрическое & $1-10^{4} \mathrm{~B} / \mathrm{M}$ & $10^{-2}-10^{2}$ & $10^{-2}-10^{3}$ & $10^{-1}-1$ & $<10^{4}$ \\
Магнитное & $10^{-10}-10^{-7}$ Тл & $10^{-6}-10^{-3}$ & $10^{-2}-10^{3}$ & $10^{-6}-10^{-4}$ & $<10$ \\
Барическое & $10^{-2}-10$ Па & $10^{-5}-10^{-2}$ & $10^{-2}-10^{3}$ & $10^{-5}-10^{-3}$ & $<10$ \\
\hline
\end{tabular}


геомагнитного поля $\Delta B \leq 500$ нТл и напряженности атмосферного электрического поля $\Delta E \approx 10^{2}-10^{5} \mathrm{~B} / \mathrm{M}$. При этом относительные значения $b=\Delta B / B_{0} \approx 10^{-2}, e=\Delta E /$ $E_{0} \approx 1-10^{3}$. При характерном времени изменения полей $10^{3}-10^{5}$ с имеем скорости изменений $\Delta \dot{B} \approx 5 \cdot 10^{-3}-5 \cdot 10^{-1}$ нТл/с, $\Delta \dot{E} \approx$ $10^{-3}-10^{2} \mathrm{~B} / \mathrm{M} \cdot \mathrm{c}, \dot{b} \approx 10^{-7}-10^{-5} \mathrm{c}^{-1}$ и $\dot{e} \approx 10^{-5}$ $-1 \mathrm{c}^{-1}$.

Для пульсаций $T \approx 10^{-2}-10^{-3}$ с значения $\Delta \dot{B} \approx 10^{-1}-10$ нТл/с, $\Delta \dot{E} \approx 10^{3}-10^{6} \mathrm{~B} / \mathrm{M} \cdot \mathrm{c}, \dot{b} \approx$ $10^{-6}-10^{-4} \mathrm{c}^{-1}$ и $\dot{e} \approx 10^{-1}-1 \mathrm{c}^{-1}$.

Важно, что органы человека обладают собственными частотами. Поэтому воздействие пульсаций с частотами, близкими к собственным, является более эффективным, а значит и труднопереносимым для организма.

Это же относится к воздействию пульсаций акустических полей (давления воздуха). Для последних амплитуда $\Delta p \approx 0,01-$ 10 Па, $T \approx 10^{-2}-10^{3} \mathrm{c}, \pi=\Delta p / p_{0} \approx 10^{-5}-10^{-2}$, $\Delta \dot{p} \approx 10^{-5}-10^{3} \Pi \mathrm{a} / \mathrm{c}$, a $\dot{\pi}=10^{-5}-10^{-3} \mathrm{c}^{-1}$.

\section{ОСНОВНЫЕ РЕЗУЛЬТАТЫ}

1. Для исследования, моделирования, прогнозирования ВАП и ВКП, выявления каналов и механизмов их воздействия на человека необходим развитый автором системный подход. Системная парадигма должна стать основой теории, методом и методологией изучения физической системы СМСМИАЗБ. Последняя является открытой динамической нелинейной системой, которой присущи нетривиальные свойства.

2. Установлено, что причинами ВАП и ВКП являются воздействия источников космического, земного и антропогенного происхождения. В ряде случаев их энергетика может быть соизмеримой. Возможно синергетическое воздействие этих источников.

3. Продемонстрировано, что систематически возникающие высокоэнергети- ческие крупномасштабные процессы на нашей планете приводят к взаимодействию подсистем в системе СМСМИАЗБ. Эти процессы играют определяющую роль в глобальном энерго- и массообмене. Они существенно влияют на биосферу, человека и общество.

4. Активные эксперименты (взрывы, старты ракет и т. п.) оказались удобными и эффективными средствами для изучения и моделирования взаимодействия подсистем, а также их воздействия на биосферу и человека.

5. Крупномасштабные неядерные военные действия, а также аварии и катастрофы на энергоемких производствах и военных базах, являясь разновидностью активных экспериментов, приводят к комплексу эффектов не только на поверхности планеты и в приземной атмосфере, но и в остальных частях атмосферы, в ионосфере и в магнитосфере, т. е. дают вклад в ВАП и ВКП, а значит, влияют на самочувствие и здоровье человека.

6. Построены основы моделей главных процессов в системе СМСМИАЗБ.

7. Основными каналами воздействия ВАП и ВКП на человека (биосферу) являются достаточно быстрые вариации (пульсации) атмосферного электрического поля, атмосферного давления и геомагнитного поля с периодами от $10^{-2}$ до $10^{3} \mathrm{c}$.

8. Эффективность воздействия на человека физическими полями увеличивается вблизи его собственных частот. Эти поля воздействуют, прежде всего, на сердечно-сосудистую систему человека и механизмы ее регуляции.

9. Для устойчивого существования высокотехнологичной цивилизации очень важна стабильность космического климата.

10. Еще более важной является предсказуемость ВАП и ВКП, их величин, продолжительностей, последствий и т. п. 


\section{Л.Ф. Чорногор \\ КАНАЛИДІЇ ВАРІАЦЙ КОСМІЧНИХ Й АТМОСФЕРНИХ ФАКТОРІВ НА БІОСФЕРУ І ЛЮДИНУ}

Обгрунтована доцільність системного підходу при вивченні каналів дії варіацій космічної та атмосферної погоди на біосферу (людину). Викладено основи системної парадигми. Встановлені причини варіацій космічної та атмосферної погоди, показано їх взаємозв'язок. Обговорюються канали дії цих варіацій на біосферу (людину). Порівнюються аперіодичні та квазіперіодичні збурення фізичних полів, які впливають на біосферу (людину).

Ключові слова: атмосферна погода, космічна погода, системний підхід, біосфера, канали дії, пульсації фізичних полів.

\section{F. Chernogor}

\section{THE WAYS IN WHICH VARIATIONS IN SPACE AND TROPOSPHERIC WEATHERIMPACT THE BIOSPHERE (HUMANS)}

The system analysis is validated to be an efficient means for studying the channels through which variations in space and tropospheric weather affect the biosphere (humans). The basics of the system analysis paradigm are presented. The causes of variations in space and tropospheric weather are determined, and the interrelations between them are demonstrated. The ways in which these variations affect the biosphere (humans) are discussed. Aperiodic and quasi-periodic disturbances in the physical fields that influence the biosphere (humans) are intercompared.

Key words: tropospheric weather, space weather, the system analysis, the biosphere, the channels of affect, the physical field pulsations.

Kharkiv V. N. Karazin National University

\section{СПИСОК ЛИТЕРАТУРЫ}

1. Бреус Т.К., Халберг Ф., Корнелиссен Ж. Влияние солнечной активности на физиологические ритмы биологических систем // Биофизика. - 1995. - 40, вып. 4. - С. 737-749.

2. Бреус Т.К., Баевский Р.М., Фунтова И.И., Никулина Г.А., Алексеев Е.В., Черникова А.Г. Влияние возмущений геомагнитного поля на реакцию адаптивного стресса у космонавтов // Косм. - 2008. 46, № 4. - С. 378-383.

3. Дружинин И.П., Хамьянова Н.Р. Солнечная активность и переломы хода природных процессов на Земле. - М.: Наука, 1969. - 224 с.

4. Дубров А.П. Геомагнитное поле и жизнь. - Л.: Гидрометеоиздат, 1974. - $176 \mathrm{c.}$

5. Лазоренко О.В., Черногор Л.Ф. Сверхшироко- полосные сигналы и процессы. Монография. - X: ХНУ им. В. Н. Каразина, 2009. - 576 с.

6. Масамуро Широ. Влияние солнечной активности на атмосферу и биосферу Земли. - М.: Наука, 1971. 209 c.

7. Мизун Ю.Г. Космос и погода. - М.: Наука, 1986. $144 \mathrm{c}$.

8. Мизун Ю.Г. Космос и здоровье. - М.: ВЕЧЕ, АСТ, 1997. -608 c.

9. Проблемы гелиобиологии. - Новосибирск: Изд-во Новосибир. гос. мед. ин-та, 1977 г. - 102 с.

10. Сидякин В.Т., Темурьянц Н.А., Макеев В.Б., Владимирский Б.М. Космическая экология. - К.: Наук. думка, 1985. - 176 с.

11. Хаснулин В.И. Космические тайны вашего самочувствия. - Новосибирск: Наука, Сибирское отделение. $-1992 .-176 \mathrm{c}$.

12. Черногор Л.Ф. Физика Земли, атмосферы и геокосмоса в свете системной парадигмы. Радиофизика и радиоастрономия. - 2003. - 8, №1 - - С. 59-106.

13. Черногор Л.Ф. Физические процессы в околоземной среде, сопровождавшие военные действия в Ираке (март-апрель 2003 г.) // Косм. наука і технологія. 2003, №2/3. - С.13-33.

14. Черногор Л.Ф. Земля - атмосфера - геокосмос как открытая динамическая нелинейная система // Там само. - №5/6. - С. 96-105.

15. Черногор Л.Ф. Геофизические эффекты и геоэкологические последствия массовых химических взрывов на военных складах в г. Артемовске // Геофиз. журн. 2004. - 26, № 4. - С. 31-44.

16. Черногор Л.Ф. Геофизические эффекты и экологические последствия пожара и взрывов на военной базе вблизи г. Мелитополь // Там само. - № 6. - С. 61-73.

17. Черногор Л.Ф. Взрывы боеприпасов на военных базах - источник экологических катастроф в Украине // Екологія і ресурси. - 2004, № 10. - С. 55-67.

18. Черногор Л.Ф. Тропический циклон как элемент системы Земля -атмосфера - ионосфера - магнитосфера // Косм. наука і технологія. - 2006. - 12, № 2/3. - C. 16-26.

19. Черногор Л.Ф. Экологические последствия массовых химических взрывов при техногенной катастрофе // Геоэкология. Инженерная геология. Гидрогеология. Геокриология. - 2006. - № 6. - С. 522-535.

20. Черногор Л.Ф. Земля - атмосфера - ионосфера магнитосфера как открытая динамическая нелинейная физическая система. 1 // Нелинейный мир. 2006. - 4, № 12. - С. 655-697.

21. Черногор Л.Ф. Земля - атмосфера - ионосфера магнитосфера как открытая динамическая нелинейная физическая система. 2 // Там само. - 2007. - 5, № 4. - С. 225-246.

22. Черногор Л.Ф. Геоэкологические последствия взрыва склада боеприпасов // Геоэкология. Инженерная геология. Гидрогеология. Геокриология. 2008. - № 4. - C. 359-369. 
23. Черногор Л.Ф. Взрывы на газопроводах и аварии на газовых хранилищах - источник экологических катастроф в Украине // Екологія і ресурси. - 2008, № 3. - С. 56-72.

24. Черногор Л.Ф. О нелинейности в природе и науке. Харьков, ХНУ им. В.Н. Каразина. - 2008. - 528 с.

25. Черногор Л.Ф. Радиофизические и геомагнитные эффекты стартов ракет - Харьков, ХНУ им. В. Н. Каразина. - 2009. - 386 с.

26. Чибисов С.М., Бреус Т.К., Левитин А.Е., Дрогова Г.М. Биологические эффекты планетарной магнитной бури // Биофизика. - 1995, 40, вып. 5. - С. 959-968.

27. Чибисов С.М. Биоритмы и гелиофизические факторы // Фундамен. исследования. - 2006, № 9. - С. $34-41$.

28. Чижевский А.Л. Земное эхо солнечных бурь. - М.: Мысль, 1976. - 367 с.

29. Ямпольский Ю.М., Зализовский А.В., Занимонский Е.М., Лизунов Г.В., Лисаченко В.Н. Связь атмосферной и космической погодных систем // Косм. наука і технологія. - 2008, 14, № 5. - С. 6-36.

30. Breus T.K., Ozheredov V.A., Syutkina E.V., Rogoza A.N.

Харьков. наи. ун-т им. В. Н. Каразина

E-mail: Leonid.F.Chernogor@univer.kharkov.ua
Some aspects of the biological effects of Space Weather // J. Atmos. and Sol-Terr Phys. - 2008. - 70, № 2-4. P. 436-441.

31. Chernogor L.F., Rozumenko V. T. Earth - Atmosphere Geospace as an Open Nonlinear Dynamical System // Radio Physics and Radio Astronomy. - 2008. - 13, № 2. - P. 120-137.

32. Encyclopedia of Nonlinear Science / Alwyn Scott, Editor.New York and London: Routledge, 2006. - P. XLIV, 1062.

33. Horsthemke W., Lefever R. Noise-induced Transitions. Theory and Applications in Physics. Chemistry and Biology. - Springer-Verlag, Berlin-Tokyo, 2006. - 318 p.

34. Kleimenova N.G., Kozyreva O.V., Breus T.K., Rapoport S.I. Pc-1 geomagnetic pulsations as a potential hazard of myocardial infarction. J. Atmos. and SolTerr Phys. - 2007. - 69. - P. 1759-1764.

35. Zalyubovsky I., Chernogor L., Rozumenko V. The EarthAtmosphere - Geospace System: Main Properties, Processes and Phenomena. Space Research in Ukraine. 20062008. The Report Prepared by the Space Research Institute of NASU-NSAU. Kyiv. - 2008. - P. 19-29. 